УДК 544.652.7:546.72

\title{
СПЕЦИФИКА ПАССИВНОГО СОСТОЯНИЯ ЖЕЛЕЗА В СЛАБОЩЕЛОЧНЫХ ВОДНЫХ СРЕДАХ РАЗЛИЧНОГО АНИОННОГО СОСТАВА
}

\author{
(C) 2017 Н. Г. Нафикова ${ }^{1}$, С. А. Калужина ${ }^{1}$, М. Ю. Санина ${ }^{2}$ \\ ${ }^{1}$ Воронежский государственный университет, Университетская пл., 1, 394018 Воронеж, Россия \\ ${ }^{2}$ Воронежский государственный педагогический университет, ул. Ленина, 86, \\ 394043 Воронеж, Россия \\ e-mail: nng2110@mail.ru
}

Поступила в редакцию 12.05.2017 г.

\begin{abstract}
Аннотация. В настоящей работе с использованием комплекса физико-химических методов проведен сравнительный анализ влияния анионного состава слабощелочных водных сред и гидродинамических условий на процессы пассивации железа. Показано, что в исследованных растворах при фиксированном $\mathrm{pH}$ природа присутствующих анионов действует более активно на процессы пассивации железа, чем гидродинамические условия.
\end{abstract}

Ключевые слова: железо, пассивность, слабощелочные среды, гидродинамические условия, анионный состав.

\section{ВВЕДЕНИЕ}

В литературе известно, что железо в слабощелочном боратном буферном растворе находится в устойчивом пассивном состоянии [1-3]. При этом присутствующая на поверхности металла пассивная плёнка имеет фазовый характер [3] и состоит не только из оксидов и гидроксидов железа, но и включает большое количество сложных гидроксидных соединений бора типа $\left(\mathrm{Fe}(\mathrm{OH})\left(\mathrm{BO}_{2}\right)_{2}\right.$, $\mathrm{Fe}_{2}\left(\left[\mathrm{~B}(\mathrm{OH})_{4}\right]_{3}(\mathrm{OH})_{3}\right)$ [3-5]. Аналогичное поведение железа наблюдается и в карбонатном буфере при соответствующем $\mathrm{pH}$, но, в последнем случае, на поверхности металла помимо гидроксидов формируется и солевой слой карбоната железа [3]. В ряде исследований [3, 6-11] отмечается способность железа пассивироваться не только в карбонатном буфере, но и в слабощелочном гидрокарбонатном растворе при достижении определенной концентрации $\mathrm{HCO}_{3}^{-}$-ионов. В этом случае состав пассивной пленки еще более усложняется за счёт присутствия в ней хемосорбированного гидроксидно-гидрокарбонатного сложного комплекса железа вида $\mathrm{Fe}_{2}(\mathrm{OH})_{2 x}\left(\mathrm{CO}_{3}\right)_{3-x} \times y \mathrm{H}_{2} \mathrm{O} . \mathrm{B}$ связи с описанными неадекватными процессами пассивации железа, меняющимися в слабощелочных растворах в зависимости от анионного состава, в настоящей работе предпринята попытка выяснить при- чину наблюдаемого эффекта на пассивном железе в системах: металл / боратный буфер (модельная) и металл / гидрокарбонатный раствор (аналог реального электролита).

\section{МЕТОДИКА ЭКСПЕРИМЕНТА}

Объектом настоящего исследования было выбрано железо-армко (0.005 \% С). В качестве рабочих растворов использовали боратный буферный $\left.0.200 \mathrm{M} \mathrm{H}_{3} \mathrm{BO}_{3}+0.050 \mathrm{M} \mathrm{Na}_{2} \mathrm{~B}_{4} \mathrm{O}_{7}(\mathrm{pH}=8.4)\right)$ и гидрокарбонатный $\mathrm{c}\left(\mathrm{NaHCO}_{3}\right)=0.075 \mathrm{M}(\mathrm{pH}=8.3)$ электролиты, в которых железо находится в пассивном состоянии [6, 7, 12].

Эксперименты осуществляли на стационарном электроде (СЭ) (железо/боратный буфер) и на вращающемся дисковом электроде (ВДЭ) при $\omega=350$ об/мин (железо/гидрокарбонатный электролит). В обоих случаях использовали классическую электролитическую трехэлектродную ячейку со свободным доступом воздуха при температуре $20 \pm 2{ }^{\circ} \mathrm{C}$.

Для получения достоверных результатов применяли комплекс физико-химических методов: электрохимических при скорости сканирования потенциала $v_{p}=2-50 \mathrm{mB} / \mathrm{c}$; физических - оптическую и сканирующую электронную микроскопию (СЭМ) - с последующим элементным ана- 
лизом состава пассивного слоя на железе на энергодисперсионной приставке к микроскопу (JEOL JSM-6510LV).

При подготовке идентичного состояния поверхности металла перед проведением каждого эксперимента механически полированные образцы подвергали катодной предполяризации в рабочем растворе при потенциале -1.000 В в течение 10 мин. В дальнейшем проводили снятие вольтамперометрической инверсионной кривой до потенциала +1.000 В. Электродные потенциалы железа измеряли относительно потенциала хлорид-серебряного электрода и затем пересчитывали на шкалу нормального водородного электрода (н.в.э.).

\section{РЕЗУЛЬТАТЫ И ОБСУЖДЕНИЕ}

Поскольку процесс пассивации железа в слабощелочных средах оказывается довольно чувствительным к изменению $\mathrm{pH}$, то анализируемые электролиты были подобраны таким образом, чтобы растворы имели аналогичное значение $\mathrm{pH}$ при различном анионном составе и обладали буферными свойствами. В связи с этим, сравнение процессов пассивации железа проводилось в системах: металл/спокойный боратный буферный раствор (общепринятая модельная система, обладающая низкой скоростью коррозии, но высокой специфичностью пассивных пленок) и железо/перемешиваемый гидрокарбонатный раствор (аналог реальной системы, в которой на поверхности типичного для слабощелочных сред оксидного пассивного слоя присутствует и солевой слой).

Анализ анодных потенциодинамических поляризационных кривых (АПК) железа-армко в боратном буферном и гидрокарбонатом растворах показал, что, последние имеют сложную, характерную для пассивирующихся металлов, форму (рис. 1) [1, $3,13]$. При этом вне зависимости от имеющих место отличий между сопоставляемыми модельной и реальной системами, на экспериментальных АПК можно выделить общие зоны: 1) активно-пассив- ных переходов с присутствием двух анодных пиков (A1 и A2), и 2) пассивности, начинающейся при достижении потенциалов пассивации $\left(E_{\text {п }}\right)$ и продолжающейся вплоть до потенциалов выделения кислорода.

Рассчитанные потенциалы и токи пиков АПК в рассматриваемых системах представлены в табл. 1. Так, потенциалы пика А1 находятся в одной области $E=(-0.400) \div(-0.350)$ В и мало зависят от таких параметров, как анионный состав и гидродинамические условия в системе железо/электролит. Вместе с тем, были отмечены сопоставимые значения скоростей процесса окисления металла в спокойном боратном буфере и движущемся гидрокарбонатном растворах.

В свою очередь, значение потенциалов и токов пика А2 зависят от состава электролита и гидродинамических условий. В спокойном боратном буферном электролите дальнейшее окисление железа происходит при более положитель-

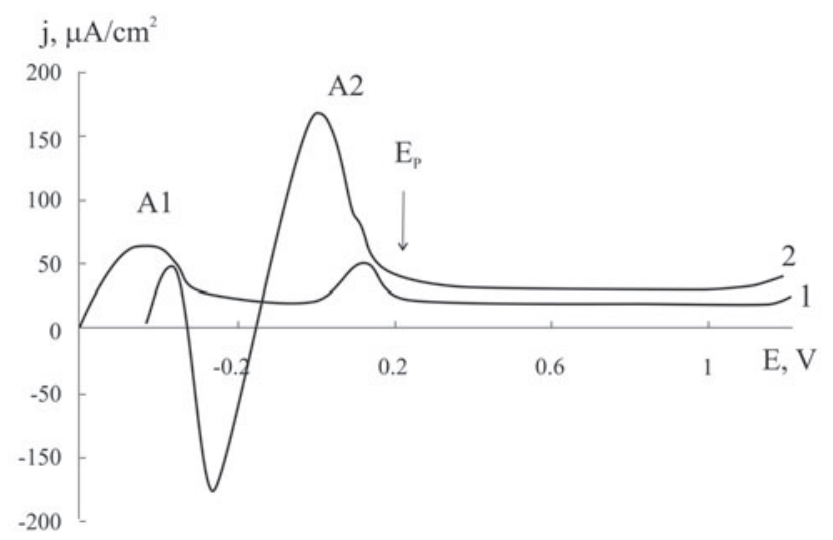

Рис. 1. Анодные потенциодинамические поляризационные кривые железа-армко в $0.200 \mathrm{M} \mathrm{H}_{3} \mathrm{BO}_{3}+0.050 \mathrm{M}$ $\mathrm{Na}_{2} \mathrm{~B}_{4} \mathrm{O}_{7}(1)$ и $0.075 \mathrm{M} \mathrm{NaHCO}_{3}$ (2). Скорость сканирования потенциала $3 \mathrm{mB} / \mathrm{c} . E_{\mathrm{p}}$ - потенциал пассивации

[Fig. 1. Anodic potentiodynamic polarization curves of iron-Armco in $0.200 \mathrm{M} \mathrm{H}_{3} \mathrm{BO}_{3}+0.050 \mathrm{M} \mathrm{Na}_{2} \mathrm{~B}_{4} \mathrm{O}_{7}$ (1) and $0.075 \mathrm{M} \mathrm{NaHCO}_{3}(2)$. The scanning speed of the potential is $3 \mathrm{mV} / \mathrm{s}$. $E_{\mathrm{p}}$ is the passivation potential]

Таблица 1. Потенциалы $(E)$ и плотности токов анодных пиков A1 и A2 $\left(j_{\max }\right)$ железа-армко в исследованных слабощелочных электролитах различного анионного состава

[Table 1. Potentials $(E)$ and current densities of the anode peaks A1 and A2 $\left(j_{\max }\right)$ of iron-Armco in the investigated electrolytes]

\begin{tabular}{|c|c|c|c|c|c|c|}
\hline $\begin{array}{c}\text { Type of } \\
\text { electrode }\end{array}$ & Electrolyte composition & $\mathrm{pH}$ & $E_{\mathrm{A} 1}, \mathrm{~V}$ & $j_{\max }(\mathrm{A} 1), \mu \mathrm{A} / \mathrm{cm}^{2}$ & $E_{\mathrm{A} 2}, \mathrm{~V}$ & $j_{\max }(\mathrm{A} 2), \mu \mathrm{A} / \mathrm{cm}^{2}$ \\
\hline $\begin{array}{c}\text { Stationary } \\
\text { electrode }\end{array}$ & $0.200 \mathrm{M} \mathrm{H}_{3} \mathrm{BO}_{3}+0.050 \mathrm{M} \mathrm{Na}_{2} \mathrm{~B}_{4} \mathrm{O}_{7}$ & 8.4 & -0.400 & 69 & 0.160 & 54 \\
\hline $\begin{array}{c}\text { Rotating disk } \\
\text { electrode }\end{array}$ & $0.075 \mathrm{M} \mathrm{NaHCO}_{3}$ & 8.3 & -0.350 & 50 & 0.050 & 158 \\
\hline
\end{tabular}


ных потенциалах $\left(E_{\mathrm{A} 2}=0.160 \mathrm{~B}\right)$ и с гораздо меньшей скоростью $\left(j_{\max }(\mathrm{A} 2)=54\right.$ мкА $\left./ \mathrm{cm}^{2}\right)$, чем на ВДЭ в гидрокарбонатном растворе $\left(E_{\mathrm{A} 2}=0.050 \mathrm{~B}\right.$, $j_{\max }(\mathrm{A} 2)=158$ мкА $\left./ \mathrm{cm}^{2}\right)$. Вместе с тем, основная закономерность заключается в том, что в неподвижном боратном буферном электролите скорости анодного процесса при потенциалах обоих анодных пиков можно считать сопоставимыми, тогда как на ВДЭ в гидрокарботаном растворе скорость анодного процесса в области потенциалов пика А2 заметно возрастает.

Следует отметить также определённые отличия формы полученных АПК, очевидно, связанные с различием гидродинамических режимов и касающиеся, прежде всего, наличия петли катодных токов, которая появляется на ВДЭ. Наблюдаемые эффекты объясняются, с одной стороны, увеличением скорости катодной реакции за счет облегчения доставки окислителя (кислорода) в приэлектродную зону, а с другой - реорганизацией пассивного слоя металла. По иному можно трактовать увеличение скорости анодного процесса в системе железо / гидрокарбонатный раствор в области потенциалов пика А2 и изменение природы пассивности в системе металл/боратный буфер. Эти факты связаны не только с изменением гидродинамических условий, но и с анионным составом электролита и, как следствие, качественным и количественным составом пассивных слоев на железе, формирование которых, согласно литературным данным [3, 5, 8], происходит стадийно.

Сопоставление потенциалов анодных пиков на поляризационных кривых с использованием известных термодинамических данных [3], позволяет качественно определить состав пассивного слоя железа в слабощелочных электролитах исследованного анионного состава. Начальным этапом формирования последнего в боратном буфере и в гидрокарбонатном растворе является образование на поверхности металла $\mathrm{Fe}(\mathrm{OH})_{2}$ :

$$
\begin{aligned}
& \mathrm{Fe}+2 \mathrm{H}_{2} \mathrm{O}=\mathrm{Fe}(\mathrm{OH})_{2}+\mathrm{H}_{2} \mathrm{O}+2 \mathrm{e}^{-} \\
& (\mathrm{E}=-0.047-0.059 \mathrm{pH}) \text {. }
\end{aligned}
$$

Далее, в зоне потенциалов пика А1 начинается формирование оксида $\gamma-\mathrm{Fe}_{2} \mathrm{O}_{3}$ :

$$
\begin{gathered}
\mathrm{Fe}(\mathrm{OH})_{2}=\gamma-\mathrm{Fe}_{2} \mathrm{O}_{3}+2 \mathrm{H}_{2} \mathrm{O}+2 \mathrm{H}^{+}+2 \mathrm{e}^{-} \\
(\mathrm{E}=0.062-0.059 \mathrm{pH}),
\end{gathered}
$$

процесс, тормозящий растворение железа. Таким образом, в условиях образования сплошной пассивной пленки, верхний слой которой состоит из $\gamma-\mathrm{Fe}_{2} \mathrm{O}_{3}$, металл должен перейти в пассивное состояние уже при потенциалах пика А1. Однако, пос- кольку и на СЭ, и на ВДЭ, формируется не сплошная пассивная пленка из-за присутствия в растворе борат- и гидрокарбонат-ионов, способных увеличивать ее дефектность за счёт адсорбции при достижении определённых потенциалов, может происходить окисление $\mathrm{Fe}(\mathrm{OH})_{2}$ до $\gamma$-FeOOH по ниже приведённой схеме:

$$
\begin{aligned}
\mathrm{Fe}(\mathrm{OH})_{2}= & \gamma-\mathrm{FeOOH}+\mathrm{Fe}^{2+}+\mathrm{OH}^{-}+\mathrm{H}_{2} \mathrm{O}+\mathrm{e}^{-} \\
& (\mathrm{E}=-0.69+0.080 \mathrm{pH}) .
\end{aligned}
$$

Образовавшийся $\gamma$-FeOOH при данных потенциалах оказывается термодинамически нестабильным и восстанавливается до $\mathrm{FeO} \cdot \mathrm{Fe}_{2} \mathrm{O}_{3}$. При этом протекает твердофазное превращение пассивного слоя:

$$
\begin{gathered}
3 \gamma-\mathrm{FeOOH}+\mathrm{H}^{+}+\mathrm{e}^{-}=\mathrm{FeO} \cdot \mathrm{Fe}_{2} \mathrm{O}_{3}+2 \mathrm{H}_{2} \mathrm{O} \\
(E=1.12-0.059 \mathrm{pH}) .
\end{gathered}
$$

Именно эта реакция может вносить существенный вклад в ускорение катодного процесса на ВДЭ и вызывать наличие катодной петли на АПК. Термодинамическая устойчивость $\gamma$-FeOOH наступает при достижении потенциалов $E \geq 0.620 \mathrm{~B}$, что соответствует пассивной зоне на АПК. Следует отметить, что наступление пассивности железа в анализируемых системах в большей степени обусловлено образованием $\gamma-\mathrm{Fe}_{2} \mathrm{O}_{3}$ :

$$
\begin{gathered}
2 \mathrm{FeO} \cdot \mathrm{Fe}_{2} \mathrm{O}_{3}+\mathrm{H}_{2} \mathrm{O}=3 \gamma-\mathrm{Fe}_{2} \mathrm{O}_{3}+2 \mathrm{H}^{+}+2 \mathrm{e}^{-} \\
(E=0.58-0.059 \mathrm{pH}) .
\end{gathered}
$$

Таким образом, исходя из полученных экспериментальных результатов, можно предположить, что образование пассивного оксидно-гидроксидного слоя на железе в слабощелочных электролитах при различных гидродинамических условиях, в общем, оказывается аналогичным и может быть представлено следующей наиболее вероятной схемой:

$$
\begin{aligned}
& \mathrm{Fe} \longrightarrow \mathrm{Fe}(\mathrm{OH})_{2} \searrow^{\gamma-\mathrm{FeOOH}} \begin{array}{l}
\gamma-\mathrm{Fe}_{2} \mathrm{O}_{3} \\
\gamma \mathrm{Fe}_{3} \mathrm{O}_{4} \longrightarrow \gamma-\mathrm{Fe}_{2} \mathrm{O}_{3}
\end{array} \\
& \alpha-\mathrm{FeOOH}
\end{aligned}
$$

Образование $\alpha$-FeOOH отмечается в условиях потока и при наличии в системе гидрокарбонат-ионов [3].

С учетом того, что в боратном буферном растворе в состав пассивной пленки на железе входят борсодержащие комплексные соединения, образующиеся при достижении определенных потенциалов: $\mathrm{Fe}(\mathrm{OH})\left(\mathrm{BO}_{2}\right)_{2}(E=-0.310 \mathrm{~B}) ; \mathrm{Fe}(\mathrm{OH})_{2}\left(\mathrm{~B}(\mathrm{OH})_{4}\right)$ $(E=0.220 \mathrm{~B}) ; \mathrm{FeOHB}_{4} \mathrm{O}_{7}(E=0.540 \mathrm{~B})$. В результате наиболее общая схема образования пассивного слоя на железе в данной системе может быть представлена в виде: 


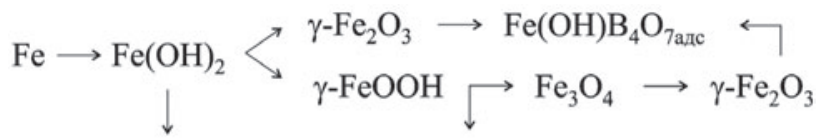

$$
\begin{aligned}
& \mathrm{Fe}(\mathrm{OH})\left(\mathrm{BO}_{2}\right)_{2} \quad \mathrm{Fe}(\mathrm{OH})_{2}\left(\mathrm{~B}(\mathrm{OH})_{4}\right)
\end{aligned}
$$

Борсодержащие соединения, входящие в состав пассивной пленки способствуют ее упрочнению и повышают стабильность пассивного металла. По результатам сканирующей электронной микроскопии (рис. 2(1)) пассивные пленки, образующиеся на железе в боратном буфере, являются достаточно тонкими и с нарушенной сплошностью.

В гидрокарбонатных средах наряду с представленными выше процессами параллельно с оксигидроксидами образуются карбонаты и гидроксокарбонаты железа [9-11], которые предшествуют и облегчают последующее образование гидроксидов на поверхности металла:

$$
\begin{gathered}
\mathrm{Fe}+\mathrm{HCO}_{3}^{-} \rightarrow \mathrm{FeCO}_{3}+\mathrm{H}^{+}+2 \mathrm{e}^{-} \\
(E=-0.750 \mathrm{~B}) .
\end{gathered}
$$

В свою очередь, как показано в [10] на основе серии результатов физических методов (Ожеспектроскопии, рентгеновской фотоэлектронной спектроскопии, сканирующей электронной микроскопии), карбонатные комплексы формируются вероятнее всего за счёт химических реакций между компонентами пассивного слоя и адсорбированными гидрокарбонат-ионами [12], локализуясь в виде кластеров на поверхности пассивного слоя, внутренняя часть которого состоит из гидроксидов железа:

$$
\begin{gathered}
\mathrm{FeOOH}+\mathrm{HCO}_{3}^{-}+\mathrm{H}^{+}=\mathrm{FeOHCO}_{3 \text { адс. }}+\mathrm{H}_{2} \mathrm{O} \\
\mathrm{Fe}_{2} \mathrm{O}_{3}+\mathrm{HCO}_{3}^{-}=\mathrm{FeOHCO}_{3 \text { адс. }}+\mathrm{OH}^{-} .
\end{gathered}
$$

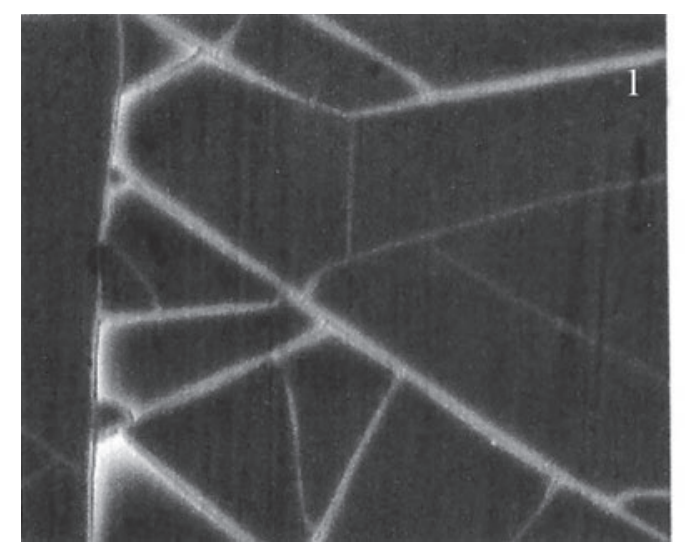

Следует отметить, что оксидные пассивные пленки на железе в гидрокарбонатном электролите настолько тонкие, что на поверхности металла видны риски после его полировки (рис. 2 (2)).

Обобщая изложенное, можно заключить, что схема образования пассивирующего слоя на железе является достаточно сложной и имеет представленный ниже вид:

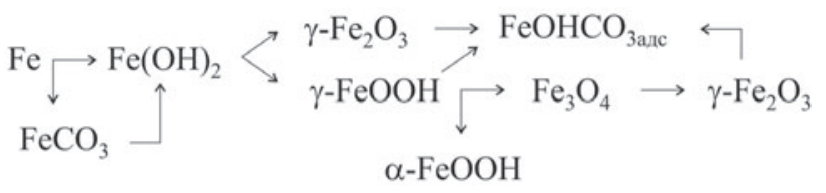

Таким образом, пассивные пленки на железе в боратном буфере и гидрокарбонатном растворе имеют сложный состав и оксидно-гидроксидную природу, а процесс их формирования на начальном этапе (в зоне потенциалов пика A1) практически не зависит от гидродинамических условий. Однако в боратном буфере образуется более плотный пассивный слой, относительно такового в гидрокарбонатном электролите.

Для определения природы лимитирующей стадии образования пассивного слоя на железе в области потенциалов анодных пиков (А1 и А2) было проанализировано влияние скорости сканирования потенциала электрода на рассматриваемый процесс в модельной (железо (СЭ)/боратный буферный раствор) и реальной (железо (ВДЭ)/гидрокарбонатный электролит) системах. Поскольку диапазон изменения скорости сканирования потенциала в анализируемых системах различен, и сопоставление экспериментальных результатов проведено для каждой системы отдельно, обобщающий вывод имеет гипотетический характер. Согласно полученным

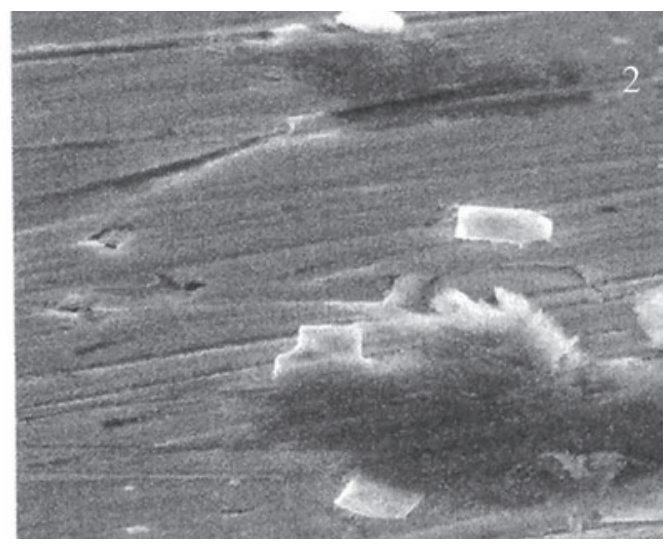

Рис. 2 Микрофотографии поверхности электрода из железа-армко после снятия анодных потенциодинамических кривых в $0.2 \mathrm{M} \mathrm{H}_{3} \mathrm{BO}_{3}+0.05 \mathrm{M} \mathrm{Na}_{2} \mathrm{~B}_{4} \mathrm{O}_{7}(1), 0.075 \mathrm{M} \mathrm{NaHCO}_{3}(2)$ при $v_{\mathrm{p}}=3 \mathrm{mB} / \mathrm{c}$. Увеличение х 1.500

[Fig. 2. Microphotographs of the surface of the iron-Armco electrode after removing the anode potentiodynamic curves in $0.2 \mathrm{M} \mathrm{H}_{3} \mathrm{BO}_{3}+0.05 \mathrm{M} \mathrm{Na}_{2} \mathrm{~B}_{4} \mathrm{O}_{7}(1), 0.075 \mathrm{M} \mathrm{NaHCO}_{3}(2)$ at $\mathrm{v}_{\mathrm{s}}=3 \mathrm{mV} / \mathrm{s}$. Increase x 1.500] 
данным (рис. 3,4$)$ форма АПК при варьировании параметра $v_{p}$ (сравнение ведется в различных анализируемых системах) не претерпевает изменений ни для системы железо/боратный буфер, ни для системы железо/гидрокарбонатный раствор.

Вместе с тем увеличение $v_{\mathrm{p}}$ приводит к росту плотности тока пиков А1 и А2 и в обеих рассматриваемых системах при практически неизменных потенциалах этих пиков (табл. 2), значения которых в боратном буферном растворе находятся вблизи 0.400 В (A1) и 0.180 В (А2), а в гидрокарбонатных электролитах определяются в зонах -0.350 В (A1)

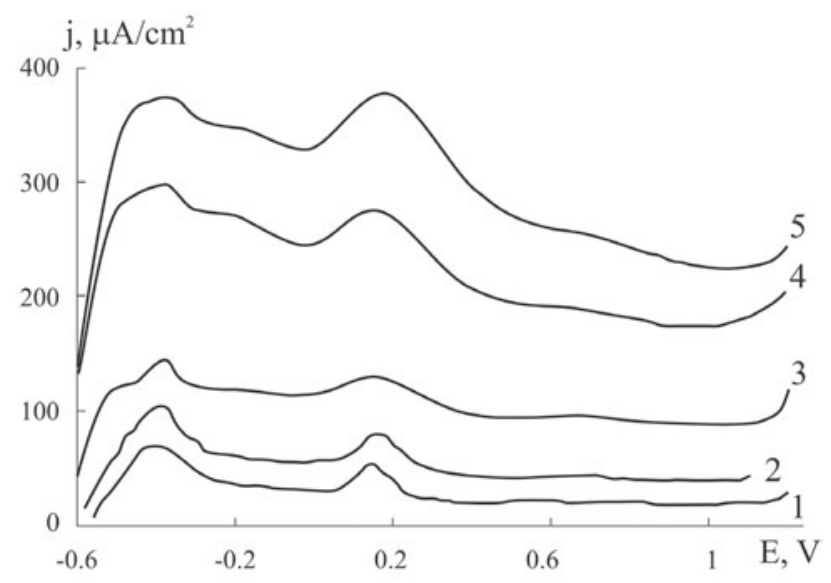

Рис. 3. Анодные потенциодинамические поляризационные кривые железа-армко в боратном буферном раствоpe $0.2 \mathrm{M} \mathrm{H}_{3} \mathrm{BO}_{3}+0.05 \mathrm{M} \mathrm{Na}_{2} \mathrm{~B}_{4} \mathrm{O}_{7}, \mathrm{pH}=8.4$, стационарный электрод, $\mathrm{d} E / \mathrm{d} \tau=1-3 \mathrm{MB} / \mathrm{c} ; 2-7 \mathrm{MB} / \mathrm{c} ; 3-10 \mathrm{MB} / \mathrm{c}$;

$$
4-20 \mathrm{mB} / \mathrm{c} ; 5-30 \mathrm{mB} / \mathrm{c}
$$

[Fig. 3. Anodic potentiodynamic polarization curves of ironArmco in a borate buffer solution $0.2 \mathrm{M} \mathrm{H}_{3} \mathrm{BO}_{3}+0.05 \mathrm{M}$ $\mathrm{Na}_{2} \mathrm{~B}_{4} \mathrm{O}_{7}, \mathrm{pH}=8.4$, stationary electrode, $\mathrm{d} E / \mathrm{d} \tau=1-3 \mathrm{mV} / \mathrm{s}$;

$2-7 \mathrm{mV} / \mathrm{s} ; 3-10 \mathrm{mV} / \mathrm{s} ; 4-20 \mathrm{mV} / \mathrm{s} ; 5-30 \mathrm{mV} / \mathrm{s}$ ] и $0.050 \mathrm{~B}(\mathrm{~A} 2)$. Описанный эффект свидетельствует о том, что стадия активного растворения железа, предшествующая пику A1, а также процесс растворения металла, протекающий в активно-пассивной области являются скорее всего квазиобратимыми $[14,15]$.

В свою очередь линеаризация зависимости $f \lg \left(j_{\max }\right)=f \lg \left(v_{p}\right)$ (рис. 5) и полученное значение $d \lg \left(j_{\max }\right) / d \lg \left(v_{p}\right) \rightarrow 0.8$ (по критерию Семирано) [14] для обоих анодных пиков в боратном буфере и для пика А2 в гидрокарбонатном растворе свидетельствуют о том, что процесс форми-

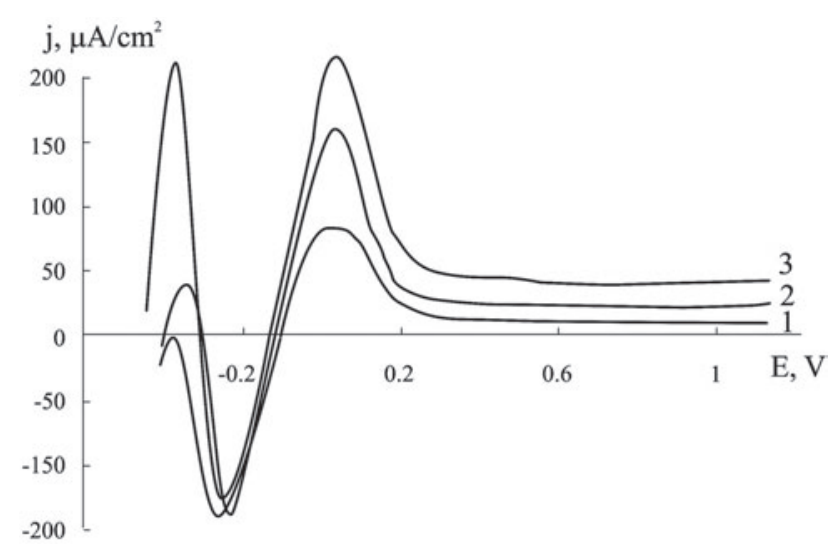

Рис. 4. Анодные потенциодинамические поляризационные кривые железа-армко в гидрокарбонатном растворе $0.075 \mathrm{M} \mathrm{NaHCO}_{3}, \mathrm{pH}=8.3$, вращающийся дисковый электрод, $\mathrm{d} E / \mathrm{d} \tau=1-2 \mathrm{mB} / \mathrm{c} ; 2-3 \mathrm{mB} / \mathrm{c} ; 3-7 \mathrm{mB} / \mathrm{c}$.

[Fig. 4. Anodic potentiodynamic polarization curves of iron-Armco in a hydrocarbonate solution $0.075 \mathrm{M} \mathrm{NaHCO}_{3}$, $\mathrm{pH}=8.3$, rotating disk electrode, $\mathrm{d} E / \mathrm{d} \tau=1-2 \mathrm{mV} / \mathrm{s} ; 2-3$ $\mathrm{mV} / \mathrm{s} ; 3-7 \mathrm{mV} / \mathrm{s}]$

Таблица 2. Влияние скорости сканирования $\left(v_{p}\right)$ на потенциалы $(E)$ и плотности тока анодных пиков А1 и A2 $\left(j_{\max }\right)$ железа-армко в исследованных слабощелочных электролитах различного анионного состава

[Table 2. The effect of the scanning rate $\left(v_{s}\right)$ on the potentials $(E)$ and the current densities of the anode peaks A1 and A2 $\left(\mathrm{j}_{\max }\right)$ of iron-Armco in the studied electrolytes]

\begin{tabular}{|c|c|c|c|c|}
\hline$v_{\mathrm{s}}, \mathrm{mV} / \mathrm{s}$ & $E_{\mathrm{A} 1}, \mathrm{~V}$ & $j_{\max }(\mathrm{A} 1), \mu \mathrm{A} / \mathrm{cm}^{2}$ & $E_{\mathrm{A} 2}, \mathrm{~V}$ & $j_{\max }(\mathrm{A} 2), \mu \mathrm{A} / \mathrm{cm}^{2}$ \\
\hline \multicolumn{5}{|c|}{$0.2 \mathrm{M} \mathrm{H}_{3} \mathrm{BO}_{3}+0.05 \mathrm{M} \mathrm{Na}_{2} \mathrm{~B}_{4} \mathrm{O}_{7}$} \\
\hline 3 & -0.400 & 69 & 0.160 & 54 \\
\hline 7 & -0.380 & 97 & 0.160 & 80 \\
\hline 10 & -0.400 & 138 & 0.180 & 128 \\
\hline 20 & -0.390 & 298 & 0.180 & 273 \\
\hline 30 & -0.390 & 373 & 0.180 & 377 \\
\hline \multicolumn{5}{|c|}{$0.075 \mathrm{M} \mathrm{NaHCO}_{3}$} \\
\hline 2 & - & - & 0.050 & 70 \\
\hline 3 & $-0,350$ & 50 & 0.050 & 158 \\
\hline 7 & $-0,350$ & 200 & 0.050 & 200 \\
\hline
\end{tabular}




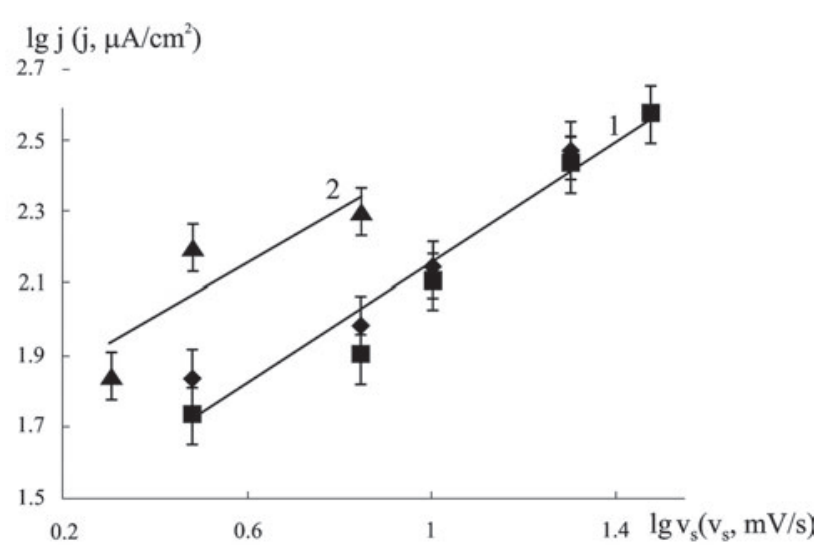

Рис. 5. Влияние скорости развертки потенциала на максимальный ток пиков на анодных поляризационных кривых железа-армко в боратном буферном растворе (1) $(\diamond-\mathrm{A} 1(E=-0.380 \mathrm{~B})$ и - $-\mathrm{A} 2(E=0.160 \mathrm{~B}))$ и гидрокарбонатном электролите (2) ( $\boldsymbol{\Delta}-\mathrm{A} 2(E=0.050 \mathrm{~B}))$

[Fig. 5. Influence of the sweep rate of the potential on the maximum peak current on the anodic polarization curves of iron-Armco in a borate buffer solution (1) $(\downarrow-$ A1 $(E=-0.380 \mathrm{~V})$ и $\mathbf{- A} 2(E=0.160 \mathrm{~V}))$ and in hydrocarbonate electrolyte (2) $(\boldsymbol{\Delta}-\mathrm{A} 2(E=0.050 \mathrm{~V}))]$

рования пассивного слоя протекает с диффузионными ограничениями и осложняется адсорбцией промежуточных соединений, предположительно боратов или карбонатов железа на поверхности оксидно-гидроксидного слоя. Литературные данные [3] и ранее установленная индифферентность скорости процесса фазообразования на железе к гидродинамическим условиям в жидкости $[8,16]$ позволяют сделать вывод о доминирующей роли твердофазной диффузии $\mathrm{Fe}^{2+}$-ионов через пассивную пленку.

\section{ВЫВОДЫ}

Таким образом, анализ экспериментальных данных показывает, что пассивация железа в боратном буферном и гидрокарбонатном растворах связана с образованием на поверхности металла фазовой оксидно-гидроксидной пассивной пленки. Процесс формирования пассивного слоя лимитируется твердофазной диффузией $\mathrm{Fe}^{2+}$-ионов через пассивную пленку и осложняется адсорбцией промежуточных соединений, предположительно боратов или карбонатов железа на поверхности оксидно-гидроксидного слоя. При этом борсодержащие комплексы входят в состав оксидно-гидроксидно- го слоя (для системы железо/боратный буферный раствор), а гидрокарбонатные комплексы присутствуют на его поверхности (в системе железо/гидрокарбонатный электролит). Варьирование гидродинамических условий не оказывает значимого влияния на процессы пассивации железа в слабощелочных средах.

\section{СПИСОК ЛИТЕРАТУРЫ}

1. Revi R. W., Ulig H. H. Corrosion and Corrosion Control. Introduction to Corrosion Science and Engineering. Published by John Wiley \& Sons, Inc. Hoboken New Jersey, 2008, 479 p.

2. Калужина С. А. Термогальваническая коррозия металлов и сплавов. Воронеж, Изд-во Воронеж. ун-та, 1988, 192 c.

3. Сухотин А. М. Физическая химия пассивирующихх пленок на железе. Ленинград, Химия, 1989, 320 с.

4. Кузнецов Ю. И., Гарманов М. Е. // Электрохимия, 1987, т. 23, № 3, с. 381-387.

5. Scharifker B. R., Habib M. A., Carbajal I. L., Bockris J. O’M. // Surf. Sci., 1986, vol. 173, № 1, pp. 97-105.

6. Blengino J. M., Keddam M., Labbe J. P., Robbiola L. // Corros. Sci., 1995. vol. 37, № 4, p. 621.

7. Нафикова Н. Г., Калужина С. А. // Конденсированные среды и межфазные границы, 2011, т. 13, № 2, c. 178-183.

8. Valand T., Sjwwall P. A. // Electrochimica Acta, 1989, vol. 34, № 2, p. 273.

9. Калужина С. А., Зибер И. В. // Коррозия: материаль, защита, 2006, № 1, с. 8-13.

10. Kaluzhina S. A., Kobanenko I. V., Sanina M. Ju., Nafikova N. G. "The Passiviny's Breakdown of Iron and Copper in Bicarbonate Solutions in Tangential and Normal Temperature Gradient's Conditions», Proceedings of symposium and Passivity and its breakdown, Pennington, N. Jersey, USA, USA, 1998, pp. 961-972.

11. Моисеева Л. С., Кузнецов Ю. И. // Зашита металлов, 1996, т. 32, № 6, с. 565-572.

12. Муратова Н. А., Калужина С. А. // Конденсированные среды и межфазныле границы, 2008, т. 10, № 3, c. 223-225.

13. Кеше Г. Коррозия металлов: физико-химические принципы и актуальные проблемы. М.: Металлургия, 1984, $400 \mathrm{c}$.

14. Иванов С. В. // Химия и технология воды, 1996, т. 18 , № 1 , с. 3-52.

15. Козин Л. Ф. Электроосаждение и растворение многовалентных металлов. Киев, Наукова думка, 1989, $464 \mathrm{c}$.

16. Муратова Н. А. Дисс. ... канд. хим. наук. Тамбов, 2006, 164 c. 


\title{
SPECIFICITY OF THE PASSIVE STATE OF IRON IN SLIGHTLY ALKALINE AQUEOUS MEDIA WITH DIFFERENT ANIONIC COMPOSITION
}

\author{
(C) 2017 N. G. Nafikova ${ }^{1}$, S. A. Kaluzhina ${ }^{1}$, M. Yu. Sanina ${ }^{2}$ \\ ${ }^{1}$ Voronezh State University, 1 University sq., 394018 Voronezh, Russia \\ ${ }^{2}$ Voronezh State Pedagogical University, 86 Lenin st., 394043 Voronezh, Russia \\ e-mail:nng2110@mail.ru
}

Received 12.05.2017

\begin{abstract}
A comparative analysis of the effect of anionic composition and hydrodynamic conditions on the passivation of iron in a borate buffer $(\mathrm{pH} 8.4)$ and hydrocarbonate $\left(\mathrm{pH} 8.3 \mathrm{c}\left(\mathrm{NaHCO}_{3}\right)=0.075\right.$ M) aqueous solutions was carried out. The experiments were performed on a stationary electrode (iron / borate buffer) and on a rotating disk electrode at $\omega=350 \mathrm{rpm}$ (iron / hydrocarbonate electrolyte). In both cases, a classical electrolytic three-electrode cell with free air access was used at a temperature of $20 \pm 2{ }^{\circ} \mathrm{C}$. To obtain reliable results, a complex of physicochemical methods was used: electrochemical methods with varying the scan speed of the potential, optical and scanning electron microscopy, X-ray microanalysis. In the media studied, the nature of the anions is very active, despite the fact that the passive state of iron is associated with the formation of oxide-hydroxide films on its surface. It is found that the formation of films occurs with diffusion limitations, and is complicated by adsorption on the surface intermediates, presumably borates or carbonates of iron. In addition boron-containing complexes are in the layer of the oxide-hydroxide (in the system iron / borate buffer), and hydrocarbonate complexes are present on the film's surface (in the system iron / hydrocarbonate electrolyte). It is established that the change in hydrodynamic conditions does not have such a significant effect on the processes of iron passivation in the studied media. Schemes for the formation of a passive layer on iron in borate and hydrocarbonate aerated solutions are presented, based on generalized data on the composition of passive films in the media studied. The proposed schemes include the formation and transformation of oxide-hydroxide and salt films on the metal surface.
\end{abstract}

Keywords: iron, passivity, slightly alkaline media, hydrodynamic conditions, anionic composition.

\section{REFERENCES}

1. Revi R. W., Ulig H. H. Corrosion and Corrosion Control. Introduction to Corrosion Science and Engineering. Published by John Wiley \& Sons, Inc. Hoboken New Jersey, 2008, 479 p.

2. Kaluzhina S. A. Thermogalvanic Corrosion of Metals and Alloys. Voronezh, Voronezh University House Publ., 1988, 192 p. (in Russian)

3. Sukhotin A. M. Physical Chemistry of Passivating Films on Iron. Leningrad, Himija Publ., 1989, 320 p. (in Russian)

4. Kuznetsov Ju. I., Garmanov M. E. Russian Journal of Electrochemistry, 1987, vol. 23, no. 3, pp. 381-387.

5. Scharifker B. R., Habib M. A., Carbajal I. L., Bockris J. O’M. Surf. Sci., 1986, vol. 173, no. 1, pp. 97-105. DOI: 10.1016/0039-6028(86)90109-3

6. Blengino J. M., Keddam M., Labbe J. P., Robbiola L. Corros. Sci., 1995. vol. 37, no. 4, p. 621. DOI: 10.1016/0010938X(94)00160-8

7. Nafikova N. G., Kaluzhina S. A. Condensed Matter and Interphases, 2011, vol. 13, no. 2, pp. 178-183. http://www. kcmf.vsu.ru/resources/t_13_2_2011_010.pdf (in Russian)
8. Valand T., Sjwwall P.A. Electrochimica Acta, 1989, vol. 34, no. 2, p. 273. DOI: 10.1016/0013-4686(89)870975

9. Kaluzhina S. A., Ziber I. V. Corrosion: Materials, Protection, 2006, no. 1, pp. 8-13.

10. Kaluzhina S. A., Kobanenko I. V., Sanina M. Ju., Nafikova N. G. “The Passiviny's Breakdown of Iron and Copper in Bicarbonate Solutions in Tangential and Normal Temperature Gradient's Conditions”, Proceedings of symposium and Passivity and its breakdown, Pennington, N. Jersey, USA, USA, 1998, pp. 961-972.

11. Moiseeva L. S., Kuznetsov Ju. I. Protection of Metals, 1996, vol. 32, no. 6, pp. 565-572.

12. Muratova N. A., Kaluzhina S. A. Condensed Matter and Interphases, 2008, vol. 10, no. 3, pp. 223-225. Available at: http://www.kcmf.vsu.ru/resources/t_10_3_2008_003.pdf (in Russian)

13. Kaesche H. Corrosion of Metals: Physicochemical Principles and Current Problems. Moscow, Metallurgija Publ., 1984, 400 p. (in Russian)

14. Ivanov S. V. Journal of Water Chemistry and Technology, 1996, vol. 18, no. 1, pp. 3-52. 
15. Kozin L. F. Electrodeposition and Dissolution of Polyvalent Metals. Kiev, Naukova Dumka Publ., 1989, 464 p. (in Russian)
16. Muratova N. A. Diss. ... cand. chem. nauk. Tambov, 2006, 164 p. (in Russian)
Нафикова Наталья Геннадьевна - соискатель кафедры физической химии химического факультета, Воронежский государственный университет; тел.:+7(960) 1029268, e-mail: nng2110@mail.ru

Калужина Светлана Анатольевна - д. х. н., профессор кафедры физической химии химического факультета, Воронежский государственный университет; тел.: +7(473) 2208538, e-mail: svetlana.kaluzhina@gmail.com

Санина Мария Юрьевна - к. х. н., доцент кафедры химии, Воронежский государственный педагогический университет; тел.: +7(473) 2554540, e-mail: smaria@ mail.ru
Nafikova Natalia G. - applicant, Physical Chemistry Department, Voronezh State University; ph: +7 (960) 1029268, e-mail: nng2110@mail.ru

Kaluzhina Svetlana A. - Dr. Sci. (Chem.), Professor, Physical Chemistry Department, Voronezh State University; ph: +7 (473) 2208538, e-mail: svetlana.kaluzhina@ gmail.com

Sanina Maria Yu. - Cand. Sci. (Chem.), Associate Professor, Chemistry Department, Voronezh State Pedagogical University; ph.: +7 (473) 2554540, e-mail: smaria@ mail.ru 